\title{
RESEARCH
}

Open Access

\section{Persistence of intramyocardially transplanted murine induced pluripotent stem cell-derived cardiomyocytes from different developmental stages}

Gabriel Peinkofer ${ }^{1,2,3^{*}}$ (D), Martina Maass ${ }^{1,4}$, Kurt Pfannkuche ${ }^{2,3,5,6}$, Agapios Sachinidis ${ }^{2,6}$, Stephan Baldus ${ }^{1}$, Jürgen Hescheler ${ }^{2}$, Tomo Saric ${ }^{2}$ and Marcel Halbach ${ }^{1}$

\begin{abstract}
Background: Induced pluripotent stem cell-derived cardiomyocytes (iPSC-CM) are regarded as promising cell type for cardiac cell replacement therapy, but it is not known whether the developmental stage influences their persistence and functional integration in the host tissue, which are crucial for a long-term therapeutic benefit. To investigate this, we first tested the cell adhesion capability of murine iPSC-CM in vitro at three different time points during the differentiation process and then examined cell persistence and quality of electrical integration in the infarcted myocardium in vivo.

Methods: To test cell adhesion capabilities in vitro, iPSC-CM were seeded on fibronectin-coated cell culture dishes and decellularized ventricular extracellular matrix (ECM) scaffolds. After fixed periods of time, stably attached cells were quantified. For in vivo experiments, murine iPSC-CM expressing enhanced green fluorescent protein was injected into infarcted hearts of adult mice. After 6-7 days, viable ventricular tissue slices were prepared to enable action potential (AP) recordings in transplanted iPSC-CM and surrounding host cardiomyocytes. Afterwards, slices were lysed, and genomic DNA was prepared, which was then used for quantitative real-time PCR to evaluate grafted iPSC-CM count.

Results: The in vitro results indicated differences in cell adhesion capabilities between day 14, day 16, and day 18 iPSC-CM with day 14 iPSC-CM showing the largest number of attached cells on ECM scaffolds. After intramyocardial injection, day 14 iPSC-CM showed a significant higher cell count compared to day 16 iPSC-CM. AP measurements revealed no significant difference in the quality of electrical integration and only minor differences in AP properties between d14 and d16 iPSC-CM.

(Continued on next page)
\end{abstract}

\footnotetext{
* Correspondence: gabriel.peinkofer@uk-koeln.de

${ }^{1}$ Department of Internal Medicine III, University Hospital of Cologne, Cologne, Germany

${ }^{2}$ Center for Physiology and Pathophysiology, Institute of Neurophysiology,

Medical Faculty, University of Cologne, Robert-Koch Str. 37, Cologne 50931, Germany

Full list of author information is available at the end of the article
}

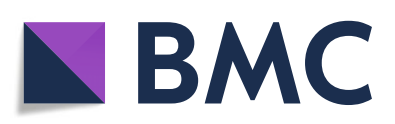

(- The Author(s). 2021 Open Access This article is licensed under a Creative Commons Attribution 4.0 International License, which permits use, sharing, adaptation, distribution and reproduction in any medium or format, as long as you give appropriate credit to the original author(s) and the source, provide a link to the Creative Commons licence, and indicate if changes were made. The images or other third party material in this article are included in the article's Creative Commons licence, unless indicated otherwise in a credit line to the material. If material is not included in the article's Creative Commons licence and your intended use is not permitted by statutory regulation or exceeds the permitted use, you will need to obtain permission directly from the copyright holder. To view a copy of this licence, visit http://creativecommons.org/licenses/by/4.0/. The Creative Commons Public Domain Dedication waiver (http://creativecommons.org/publicdomain/zero/1.0/) applies to the data made available in this article, unless otherwise stated in a credit line to the data. 


\begin{abstract}
(Continued from previous page)
Conclusion: The results of the present study demonstrate that the developmental stage at the time of transplantation is crucial for the persistence of transplanted iPSC-CM. IPSC-CM at day 14 of differentiation showed the highest persistence after transplantation in vivo, which may be explained by a higher capability to adhere to the extracellular matrix.
\end{abstract}

Keywords: Induced pluripotent stem cell-derived cardiomyocytes, Cell therapy, Cell persistence

\section{Background}

Ischemic heart disease belongs to the most frequent causes of death worldwide [1]. Despite advances in medical and interventional treatment resulting in an improved myocardial function and survival, there is still no treatment available to successfully regenerate the lost heart muscle. Pluripotent stem cell-derived cardiomyocytes are considered a promising future option for regeneration of damaged heart tissue. Induced pluripotent stem cells (iPSC) possess similar differentiation capabilities as embryonic stem cells $[2,3]$ and can be differentiated into derivatives of all three germ layers including cardiomyocytes (iPSC-CM) [4,5]. Recent advances in cell culture techniques allow for the derivation of large numbers of highly purified iPSC-CM $[6,7]$. Experiments in small and large animal models of myocardial infarction (MI) showed safe application and an improved heart function after transplantation of iPSC-CM [8-12]. As result of these preclinical studies, the first clinical trials using human iPSC-CM were recently approved by regulatory authorities [13]. However, the mechanisms behind cell homing into recipient cardiac tissue or cell loss are poorly understood and the poor cell persistence after transplantation remains an unsolved challenge.

Several studies demonstrated that the percentage of cells remaining in the host tissue after transplantation is very low and ranges approximately between 2 and $11 \%$. In a study using intramyocardial injection technique in a rat model of MI, the number of neonatal rat cardiomyocytes detected after 3 weeks varied between $8.2 \pm 3.6 \%$ in a low cell dose group $\left(5 \times 10^{6}\right.$ cells, injected into five sites of the infarction border zone) and $9.6 \pm 2.4 \%$ in a high cell dose group $\left(25 \times 10^{6}\right.$ cells, injected into five sites of infarction border zone) [14]. Hou et al. tested different administration routes in an ischemic swine model. Intramyocardial injection of peripheral blood mononuclear cells showed highest cell persistence (11 \pm $3 \%)$ in comparison to intracoronary $(2.6 \pm 0.3 \%)$ and interstitial retrograde coronary venous administration $(3.2 \pm 1 \%) 1 \mathrm{~h}$ after cell delivery [15]. The optimal delivery route of cells will also depend on clinical settings like planned open chest surgery or catheter interventions. After direct myocardial injection, cells can be lost immediately because of leakage through the injection channel [16], and after intramyocardial and intracoronary injection, cells can be washed away through the circulation [15, 17]. Besides immediate cell loss after transplantation also ischemia and apoptotic cell death decrease cell retention $[18,19]$. Co-transplantation of different cell types like smooth muscle cells, fibroblasts or MSCs may influence cell retention. Co-transplantation of embryonic stem cell-derived cardiomyocytes (ESCM) with mesenchymal stem cells (MSC) combined in in vitro grown micro tissue increased cell retention more than tenfold within the first days after transplantation [20].

Among other factors, the developmental stage of transplanted cells has a major effect on their persistence and integration. Adult cardiomyocytes do not survive transplantation [19], while juvenile native cardiomyocytes and immature iPSC-CM survive and integrate functionally [19, 21, 22]. Even during early development, cardiomyocytes undergo substantial morphological and physiological changes [23-25], which influence their fate after transplantation. Fetal murine cardiomyocytes at an intermediate stage (day 14.5 post coitum) have the highest persistence and quality of electrical integration as compared to earlier (day 12.5 post coitum) and later stages (day 18.5 post coitum) [26]. iPSC-CM undergo similar developmental changes in vitro as native cardiomyocytes in vivo [27], making it likely that the fate of transplanted cells will by significantly affected by their specific developmental stage.

Therefore, in the present study, we analyzed adhesion of murine iPSC-CM from different stages of differentiation (days 14, 16, and 18) to fibronectin-coated culture dishes and native cardiac extra cellular matrix (ECM) scaffolds in vitro and cell persistence and quality of electrical integration after transplantation into infarcted mouse heart in vivo. Our data demonstrate that day 14 iPSC-CM exhibit the highest adhesion ability in vitro and the highest survival rate with good functional integration potential in vivo. These results shed new light on stage-dependent $\mathrm{iPSC}-\mathrm{CM}$ persistence and integration.

\section{Methods}

iPS cell culture and cardiac differentiation

The murine iPS cell line TiB7.4 was used, which was generated from murine tail tip fibroblasts isolated from $129 \mathrm{~S} 4 / \mathrm{Sv} 4 \mathrm{JaeJ} \times \mathrm{C} 57 \mathrm{Bl} / 6$ mice [28]. Cells were transfected with the $\alpha$-PIG plasmid vector containing the 
PAC-(encoding puromycin $N$-acetyl-transferase) and IRES (internal ribosomal entry site) flanked eGFP-gene under control of the $\alpha$-Myosin Heavy Chain promoter (GenBank Accession No. U71441), as described previously [22, 29]. iPS cells were grown on inactivated murine embryonic fibroblasts in DMEM supplemented with $15 \%$ fetal calf serum, $1 \times$ non-essential amino acids, 2 $\mathrm{mM}$ L-glutamine, $100 \mu \mathrm{M} ß$-mercaptoethanol (all reagents were purchased from Thermo Fisher Scientific, Waltham, USA), and $1000 \mathrm{IU} / \mathrm{ml}$ leukemia-inhibiting factor (Merck Millipore, Billerica, USA). Murine embryonic fibroblasts were prepared from transgenic C57BL6 mice carrying a neomycin resistance gene at embryonic day 14.5 and inactivated by mitomycin $C$ treatment. iPS cells were passaged every second or third day; cells were trypsinized and $0.5 \times 10^{5}$ cells were added to a 6 - $\mathrm{cm}$ dish with preplated murine embryonic fibroblasts $\left(0.8 \times 10^{5} /\right.$ dish $)$.

For cardiac differentiation, $1 \times 10^{6}$ iPS cells were suspended in $10 \mathrm{~cm}$ bacterial dishes in $14 \mathrm{ml}$ Iscove's modified Dulbecco's medium (IMDM) supplemented with $20 \%$ fetal calf serum, $100 \mu \mathrm{M}$ ß-mercaptoethanol, $1 \times$ non-essential amino acids, and $50 \mu \mathrm{g} / \mathrm{ml}$ ascorbic acid (Thermo Fisher Scientific) and placed on a horizontal shaker for 2 days to allow embryoid body formation. After 2 days, 30,000 embryoid bodies were transferred to a spinner flask filled with $200 \mathrm{ml}$ of IMDM differentiation medium. Starting at day $9,8 \mu \mathrm{g} / \mathrm{ml}$ puromycin (InvivoGen Europe, Toulouse, France) was added for cardiomyocyte purification, and medium with fresh puromycin was changed every second day. At day 14, day 16 , or day 18 , purified iPSC-CM clusters were dissociated into single cardiomyocytes with $0.25 \%$ trypsinEDTA (Thermo Fisher Scientific) supplemented with 5 $\mathrm{U} / \mathrm{ml}$ of DNAse I (Sigma-Aldrich, Taufkirchen, Germany) for further use.

\section{Quantification of iPSC-CM adhesion in vitro}

At day 14, day 16, and day 18 of cardiac differentiation, dissociated iPSC-CM were plated on fibronectin-coated $\left(20 \mu \mathrm{g} / \mathrm{ml}\right.$ for $2 \mathrm{~h}$ at $37^{\circ} \mathrm{C}$; Sigma-Aldrich) 3-cm dishes. In each approach, two drops containing 20,000 cells in $100 \mu \mathrm{L}$ cell culture medium each were added to separate fibronectin-coated cell culture dishes. One drop was incubated for $5 \mathrm{~min}$ and the other for $10 \mathrm{~min}$. Afterwards, the dishes were washed with $1.5 \mathrm{ml} \mathrm{PBS}^{-/-}$for $1 \mathrm{~min}$. Cells attached to the surface were counted using a microscope (Axiovert 200, Zeiss, Oberkochen, Germany) and the ImageJ program [30].

\section{Preparation of ventricular slices}

Ventricular slices were prepared as described before [31, 32]. The hearts were resected and perfused with ice-cold Tyrode solution (composition in mmol/l: $\mathrm{NaCl} 136, \mathrm{KCl}$
5.4, $\mathrm{NaH}_{2} \mathrm{PO}_{4}$ 0.33, $\mathrm{MgCl}_{2}$ 1, glucose 10, Hepes 5, 2,3butanedione monoxime 30; $\mathrm{pH} 7.4$ adjusted with $\mathrm{NaOH}$; all chemicals were purchased from Sigma Aldrich). Ventricles were separated from the atria and embedded in 4\% low melt agarose (Roth, Karlsruhe, Germany). Short axis slices $(150 \mu \mathrm{m})$ were cut with a microtome (Leica VT1000S; Leica Microsystems, Wetzlar, Germany) and stored in Tyrode solution containing $0.9 \mathrm{mmol} / \mathrm{L} \mathrm{Ca}^{2+}$ for $30 \mathrm{~min}$ on ice. Afterwards, slices were either frozen for decellularization or transferred to DMEM at $37^{\circ} \mathrm{C}$ aerated with $95 \% \mathrm{O}_{2}$ and $5 \% \mathrm{CO}_{2}$ and allowed to recover for another $30 \mathrm{~min}$ before action potential (AP) recordings.

\section{Decellularization of ventricular slices}

Ventricular heart slices were frozen at $-20^{\circ} \mathrm{C}$ for at least $24 \mathrm{~h}$. To remove all cellular components from the ECM structure, slices were first rinsed with $\mathrm{PBS}^{-/-}$at $37^{\circ} \mathrm{C}$ for $15 \mathrm{~min}$. Afterwards, treatment was continued with $1 \%$ SDS (SDS, Sigma Aldrich) in $\mathrm{PBS}^{-1-}$ for $2 \mathrm{~h}$ at $37^{\circ} \mathrm{C}$. SDS was washed out with $\mathrm{PBS}^{-1-}$ for $15 \mathrm{~min}$ at $37^{\circ} \mathrm{C}$. Subsequently, slices were rinsed with $3 \%$ Triton $\mathrm{x}-100$ (3\% Triton X-100, Sigma Aldrich) in $\mathrm{PBS}^{-1-}$ for $2 \mathrm{~h}$ at $37^{\circ} \mathrm{C}$. Finally, Triton X-100 was washed out with $\mathrm{PBS}^{-/-}$ for $30 \mathrm{~min}$ at $37^{\circ} \mathrm{C}$. Decellularized ECM scaffolds were used immediately or stored in $\mathrm{PBS}^{-/-}$at $4{ }^{\circ} \mathrm{C}$.

\section{Recellularization of ECM scaffolds}

ECM scaffolds were carefully placed in a custom made "funnel dish" (Fig. 1). Funnel dishes were printed using Ultimaker2 3D printer (Ultimaker, Utrecht, Netherlands). Subsequently, $100 \mu \mathrm{l}$ of cell suspension containing $2.0 \times 10^{5}$ day 14 , day 16 , or day 18 iPSC-CM in iPSC-CM cell culture medium were added. Funnel dishes were incubated at $37^{\circ} \mathrm{C}$ with $5 \% \mathrm{CO}_{2}$ for $1 \mathrm{~h}$. Scaffolds were rinsed with iPSC-CM cell culture medium for $5 \mathrm{~min}$ and incubated in iPSC-CM cell culture medium at $37^{\circ} \mathrm{C}$ and $5 \% \mathrm{CO}_{2}$ for 7 days. Medium was changed every second day. Afterwards, genomic DNA from recellularized ECM scaffolds was isolated for cell quantification using qPCR.

\section{DNA isolation and quantitative PCR analysis}

To quantify cell persistence and adhesion, genomic DNA from the whole hearts, dissociated iPSC-CM and recellularized ECM scaffolds were isolated using Qiagen DNeasy Blood \& Tissue kit (Qiagen, Hilden, Germany). Quantitative real-time PCR was performed as described before $[14,33]$. In short, the primer against the PAC-gene (Custom TaqMan ${ }^{\circ}$ Gene Expression Assay MousePURO, Applied Biosystems, Life Technologies Corporation, Carlsbad, USA; Sequence for product design: ATGA CCGAGTACAAGCCCACGGTGCGCCTCGCCACCCGCG ACGACGTCCCCAGGGCCGTACGCACCCTCGCCGCC 


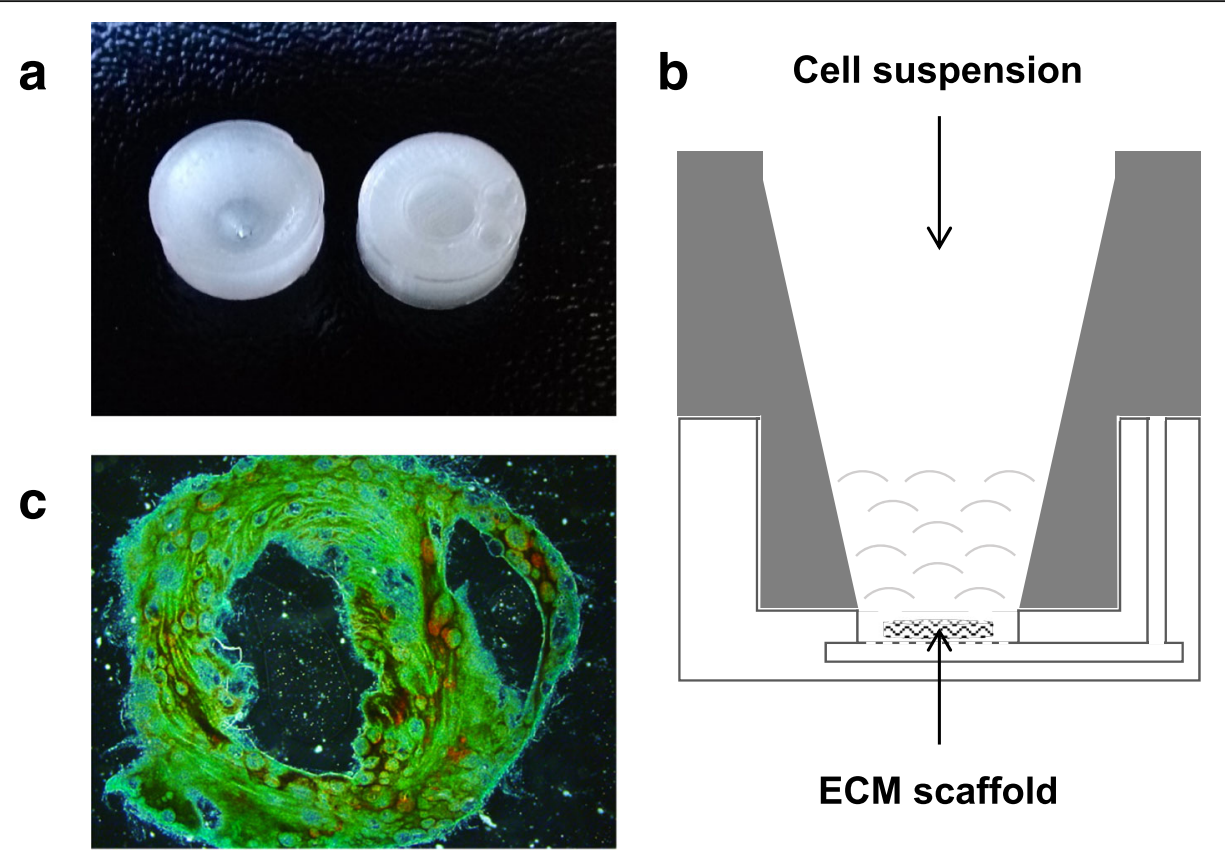

Fig. 1 Decellularized ECM scaffold on a funnel dish. a Representative picture of a custom-made funnel dish, upper part left, and lower part right. b Schematic view of a funnel dish. c Decellularized ECM scaffold stained with Masson-Trichrome-Staining. Green: collagen, Red: keratin and muscle fibers, Pink: cytoplasm

GCGTTCGCCGACTACCCCGCCACGCGCCACACCGT CGATCCGGACCGCCACATCGAGCGGGTCACCGA GCTGCAAGAACTCTTCCTCACGCGCGTCGGGCTCG ACATCGGCAAGGTGTGGGTCGCGGACGACGGCG CCGCGGTGGCGGTCTGGACCACGCCGGAGAGCG TCGAAGCGGGGGCGGTGTTCGCCGAGATCGGCCC GCGCATGGCCGAGTTGAGCGGTTCCCGGCTGGC CGCGCAGCAACAGATGGAAGGCCTCCTGGCGC CGCACCGGCCCAAGGAGCCCGCGTGGTTCCTGGCC ACCGTCGGCGTCTCGCCCGACCACCAGGGCAAGGG TCTGGGCAGCGCCGTCGTGCTCCCCGGAGTGGAGG CGGCCGAGCGCGCCGGGGTGCCCGCCTTCCTGGAGA CCTCCGCGCCCCGCAACCTCCCCTTCTACGAG CGGCTCGGCTTCACCGTCACCGCCGACGTCGA GGTGCCCGAAGGACCGCGCACCTGGTGCATGACC CGCAAGCCCGGTGCCTGA) was used to detect iPSCCM. As housekeeping gene, Gene Expression Assay MouseTuba4a (Mm00849767_s1, Applied Biosystems) was used. Samples with known numbers of PAC-positive iPSC-CM and PAC-negative native ventricular cardiomyocytes were used to derive a calibration curve for the calculation of $\mathrm{PAC}$-positive/total DNA ratio in recipient hearts. For PAC-positive iPSC-CM detection on ECM scaffolds, iPSC-CM serial dilution was used to generate a calibration curve for the calculation of absolute cell numbers of remaining PAC-positive cells.

\section{Microarray gene expression analysis}

Microarray analysis was done at the transcriptomics core facility at the Center for Molecular Medicine Cologne
(CMMC), as described previously [34, 35]. Briefly, total RNA for global gene expression analysis was extracted from dissociated day 14, day 16, and day 18 iPSC-CM using RNeasy mini kit (Qiagen, Hilden, Germany). For each analysis, triplicates made of different cell batches were used. For microarray labeling, $12.5 \mu \mathrm{g}$ amplified RNA was hybridized on Mouse Genome 430 version 2.0 arrays (Affymetrix, Santa Clara, CA, USA). After staining (Affymetrix Fluidics Station-450), arrays were scanned with Affymetrix Gene-Chip Scanner-3000-7G, while quality control matrices were confirmed with Affymetrix GCOS software. Statistical data analysis was performed using the Transcriptome Analysis Console (TAC) software from Applied Biosystems (Applied Biosystems, Foster City, CA, USA). Comparison was performed by the ANOVA method (ebayes) to generate the differentially regulated transcripts with at least a 2 -fold change $(p$ value $<0.05)$. For more details, please see supplemental methods.

\section{iPSC-CM transplantation}

At day 14 and day 16 of cardiac differentiation, iPSC$\mathrm{CM}$ were transplanted into the infarcted hearts of syngenic female 129S4/Sv4JaeJ $\times$ C57Bl/6 mice (> 8 weeks) as described before [36]. After permanent LAD ligation, dissociated iPSC-CM were injected with a Hamilton syringe ( $\mathrm{H}$. Faust $\mathrm{GmbH}$, Rheinbach, Germany) attached to a 29-gauge needle (Sigma-Aldrich) into two sites (500, 000 cells $/ 10 \mu \mathrm{l} 0.9 \% \mathrm{NaCl}$ solution at each site) of the infarct border zone. For further analysis, animals were 
kept alive for 6-7 days after surgery. All experiments conformed to the guidelines of the local animal welfare committee and to the Directive 2010/63/EU of the European Parliament.

\section{AP recordings}

Intracellular AP recordings in ventricular slices were performed with sharp glass microelectrodes (15-40 M $\Omega$ when filled with $3 \mathrm{~mol} / \mathrm{l} \mathrm{KCl}$; World Precision Instrument, Sarasota, USA) as described before [22, 37]. eGFP-positive iPSC-CM could be identified by their green fluorescence, enabling a precise positioning of the recording electrode in graft or host tissue. A defined beating frequency was applied with a SD9 square pulse stimulator (Grass Technologies, West Warwick, USA) using a unipolar custom-made stimulation electrode. Signals were amplified with a SEC-10LX amplifier (npi electronic, Tamm, Germany) and acquired with the Pulse software (HEKA, Lambrecht/Pfalz, Germany). Data were analyzed offline with Mini Analysis (Synaptosoft, Fort Lee, USA). Because electrical excitation originated from host tissue, we determined the temporal interdependency of stimulation artifacts and APs recorded intracellularly in transplanted cardiomyocytes as indicator of an electrical integration. The quality of electrical integration could be assessed by the maximal stimulation frequency without conduction blocks, i.e., the maximal stimulation frequency leading to a 1:1 generation of APs after every stimulus.

\section{Statistics}

All data are presented as mean \pm S.E.M. Two groups of data were tested for statistical significance by Student's $t$ test or, if normality test failed, by Mann-Whitney rank sum test. More than two groups were tested by one-way ANOVA with post-test or, if normality test failed, by one-way ANOVA on ranks with post-test. A two-sided $p$ value $<0.05$ was considered statistically significant. SigmaStat (Systat, Erkrath, Germany), GraphPad Prism 8.0 (GraphPad Software, San Diego, USA), and SPSS Statistics version 23 (IBM, Armok, NY, USA) were used for all calculations.

\section{Results}

\section{Adhesion of iPSC-CM to fibronectin-coated dishes}

To test differences in adhesion capability of iPSC-CM at day 14, day 16, and day 18 of differentiation, which might contribute to differences in persistence after transplantation, their attachment to fibronectin-coated dishes was assessed in vitro. After $5 \mathrm{~min}$ of cultivation, $3542 \pm 999$ cells at day $14,2430 \pm 1093$ cells at day 16 and $2532 \pm 1017$ cells at day 18 of differentiation remained attached to the surface of the fibronectincoated dishes. After $10 \mathrm{~min}$ of cultivation, $8634 \pm 1824$ cells at day $14,4288 \pm 1134$ cells at day 16 , and $6442 \pm 2668$ cells at day 18 of differentiation were attached (Fig. 2). The differences between the three groups were not statistically significant $(5 \mathrm{~min}, p=$ 0.709; 10 min, $p=0.326$ ).

Cell diameter of attached round shaped iPSC-CM was similar at all time points. Day 14 iPSC-CM showed an average diameter of $65 \pm 2 \mu \mathrm{m}$, day 16 iPSC-CM of $68 \pm 2 \mu \mathrm{m}$, and day 18 iPSC-CM of $65 \pm$ $2 \mu \mathrm{m}(n=53, p=0.285)$.

\section{Adhesion of iPSC-CM to ECM scaffolds}

To further investigate the adhesion capability of iPSCCM from different stages (day 14, day 16, and day 18), attachment to ECM scaffolds gained from decellularized ventricular slices was tested. Six samples of iPSC-CM at day 14 of differentiation were analyzed. In two samples, the number of attached cells was below the detection limit of the qPCR method (i.e., below 1000 cells). In the other four samples in average $2671 \pm 71$ iPSC-CM per slice could be detected after 7 days of cultivation on ECM scaffolds. When iPSC-CM at day 16 of differentiation were examined, the number of attached cells was below the detection limit in five out of six samples. In the remaining sample, 1076 iPSC-CM were detected. The number of attached iPSC-CM at day 18 of differentiation was below the detection limit in all samples $(n=$ 5) (Fig. 3).

\section{Persistence of transplanted iPSC-CM}

To test cell persistence after transplantation of iPSC-CM at different developmental stages, day 14 and day 16 iPSC-CM were transplanted into the infarct border zone of $N=14$ and $N=11$ recipient mice, respectively. Day 18 iPSC-CM were not included in these in vivo experiments due to the very low attachment to ECM scaffolds observed in vitro. Areas of green fluorescent transplanted cells were clearly visible by fluorescence microscopy, revealing the survival of iPSC-CM at 7 days after transplantation (Fig. 4a). Quantification of persistence by qPCR revealed that iPSC-CM transplanted at day 14 of differentiation had an approximately 7 -fold higher persistence in host tissue than iPSC-CM transplanted at day 16 of differentiation (Fig. 4b), with an average of 57, $173 \pm 8343$ remaining day 14 iPSC-CM per host ventricle and $7983 \pm 3241$ remaining day 16 iPSC-CM $(p<0.001$, Fig. 4b). This corresponded to a mean persistence of $5.7 \%$ of transplanted day 14 iPSC-CM and $0.8 \%$ of day 16 iPSC-CM. A maximal number of 308,713 (30.9\%) and a minimal number of 7244 cells $(0.7 \%)$ were detected after transplantation of day 14 iPSC-CM. For day 16 iPSC-CM, the maximal number was 39,135 (3.9\%) that was observed in only one animal and the minimal number 1183 iPSC-CM (0.11\%). 


\section{a}
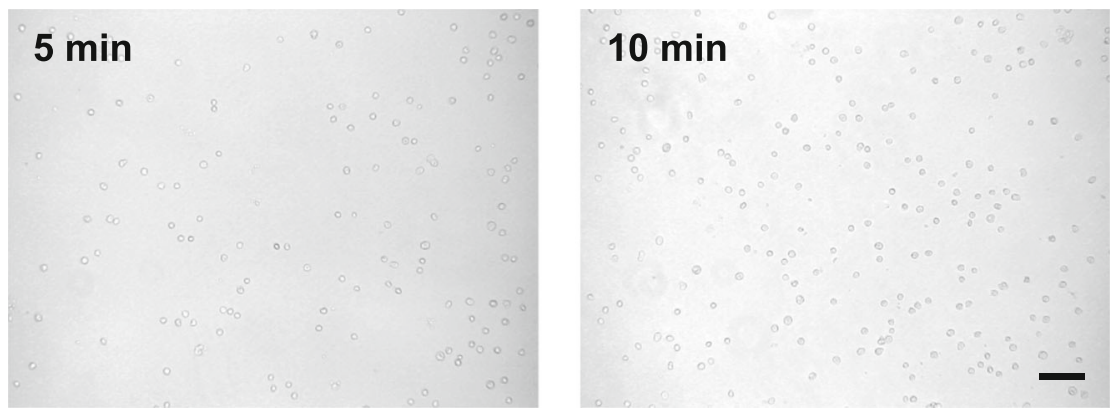

b

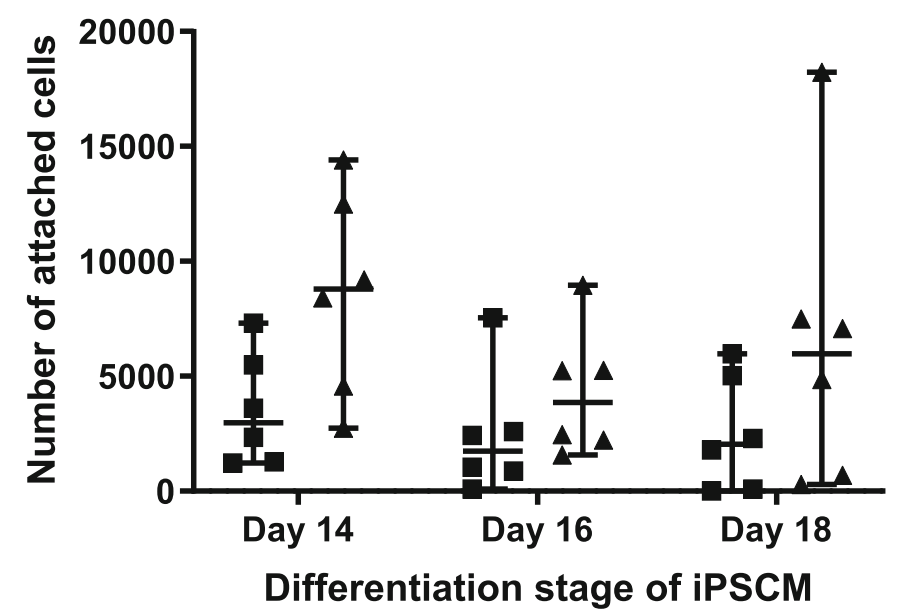

- 5 min

$\Delta \quad 10 \mathrm{~min}$

Fig. 2 Adhesion of iPSC-CM to fibronectin-coated dishes. a Representative pictures of attached iPSC-CM 5 min (left panel) and 10 min (right panel) after plating on fibronectin-coated cell culture dishes. Scale bar $100 \mu \mathrm{m}$. b Number of attached iPSC-CM plated at different stages (14 days, 16 days, and 18 days after starting the differentiation process). 20,000 cells were plated in $100 \mu \mathrm{l}$ drops per dish. Cells were photographed and counted 5 (square) or 10 (triangle) minutes after plating. All data are presented as mean + S.E.M. Statistical analysis was performed using one-way ANOVA with post-test, 5 min: $p=0.709 ; 10$ min $p=0.326$

\section{Functional integration of transplanted iPSC-CM}

Sharp electrode action potential measurements in healthy heart tissue as well as in green fluorescent iPSC-CM (Fig. 5a) were performed to evaluate the quality of electrical integration of transplanted iPSC-CM into the recipient myocardium and to analyze electrophysiological properties of transplanted day $14(N=6)$ and day $16(N=8)$ iPSC-CM in comparison to host $(N=8)$ cardiomyocytes.

The maximal stimulation frequency without conduction block, indicating the quality of integration of transplanted cells, was not significantly different between the two transplanted groups and was $8.3 \pm 1.2 \mathrm{~Hz}$ for day 14 iPSC-CM and $7.6 \pm 0.9 \mathrm{~Hz}$ for day $16 \mathrm{iPSC}-\mathrm{CM}$ ( $p=$ $0.653)$. The maximal stimulation frequency without conduction block in the surrounding native heart tissue was significantly higher than in both iPSC-CM groups $(11.9 \pm 1.2 \mathrm{~Hz}, p=0.038$, Fig. 5b).

Analyses of action potential properties showed significant differences between host tissue and iPSC-CM (Fig. 5c) in amplitude (host tissue $83.3 \pm 3.4 \mathrm{mV}$, day $14 \mathrm{iPSCM} 47.4 \pm$ $3.4 \mathrm{mV}$, day $16 \mathrm{iPSCM} 53.2 \pm 3.6 \mathrm{mV}, p<0.001$ ), maximal diastolic potential (MDP; host tissue $-67.0 \pm 3.9 \mathrm{mV}$, day 14
iPSCM $-45.4 \pm 2.3 \mathrm{mV}$, day $16 \mathrm{iPSCM}-51.1 \pm 3.2 \mathrm{mV}, p<$ 0.001 ) and upstroke velocity ( $V_{\text {max }}$; host tissue $110.6 \pm 16.2$ $\mathrm{mV}$, day $14 \mathrm{iPSCM} 30.6 \pm 8.6 \mathrm{mV}$, day $16 \mathrm{iPSCM} 38.2 \pm 6.6$ $\mathrm{mV}, p<0.001$; Fig. $5 \mathrm{~d}$, e). No significant differences were found between host tissue and IPSCM in action potential duration at 50\% of repolarization (APD50; host tissue $12.6 \pm$ $1.7 \mathrm{~ms}$, day $14 \mathrm{iPSCM} 15.4 \pm 1.4 \mathrm{~ms}$, day $16 \mathrm{iPSCM} 11.5 \pm$ $0.9 \mathrm{~ms}, p=0.097$ ) and $90 \%$ of repolarization (APD90; host tissue $64.5 \pm 4.0 \mathrm{~ms}$, day $14 \mathrm{iPSCM} 54.6 \pm 7.5 \mathrm{~ms}$, day 16 iPSCM $72.0 \pm 8.3 \mathrm{~ms}, p=0.238$; Fig. $5 \mathrm{~d}$, e).

Comparison of action potential properties between transplanted day 14 and day 16 iPSC-CM revealed no significant differences between the two groups in amplitude (day 14 iPSCM $47.4 \pm 3.4 \mathrm{mV}$, day 16 iPSCM $53.2 \pm 5.3 \mathrm{mV}, p=0.916$ ), MDP (day 14 iPSCM $-45.4 \pm$ $2.3 \mathrm{mV}$, day $16 \mathrm{iPSCM}-51.1 \pm 3.0 \mathrm{mV}, \quad p=0.149$ ), APD90 (day 14 iPSCM $54.6 \pm 7.5 \mathrm{~ms}$, day 16 iPSCM $72.0 \pm 8.3 \mathrm{~ms}, p=0.141)$, and upstroke velocity ( $V_{\max }$; day $14 \mathrm{iPSCM} 30.6 \pm 8.6 \mathrm{~V} / \mathrm{s}$, day $16 \mathrm{iPSCM} 38.2 \pm 6.6 \mathrm{~V} /$ s, $p=0.496$; Fig. $5 d$, e). However, a significant difference was found in APD50 (day 14 iPSCM 15.4 $\pm 1.4 \mathrm{~ms}$, day 16 iPSCM $11.5 \pm 0.9$ ms, $p=0.03$; Fig. $5 d$, e). 
a
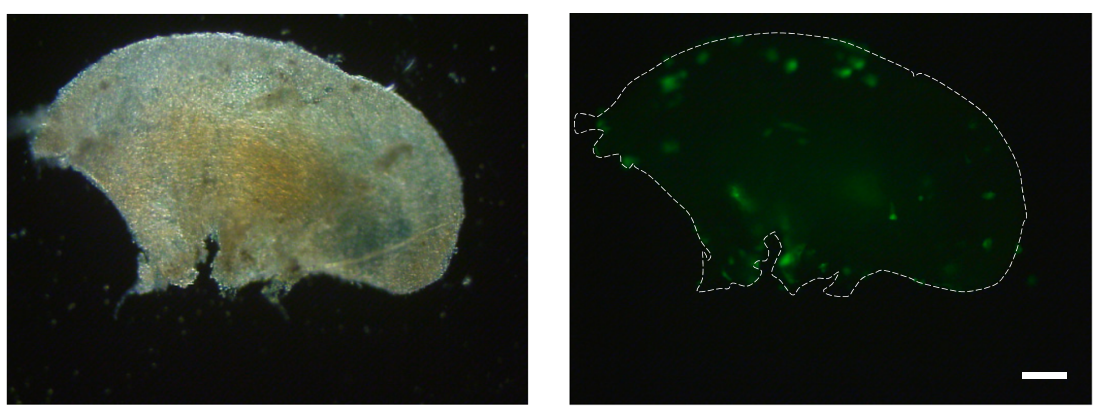

b

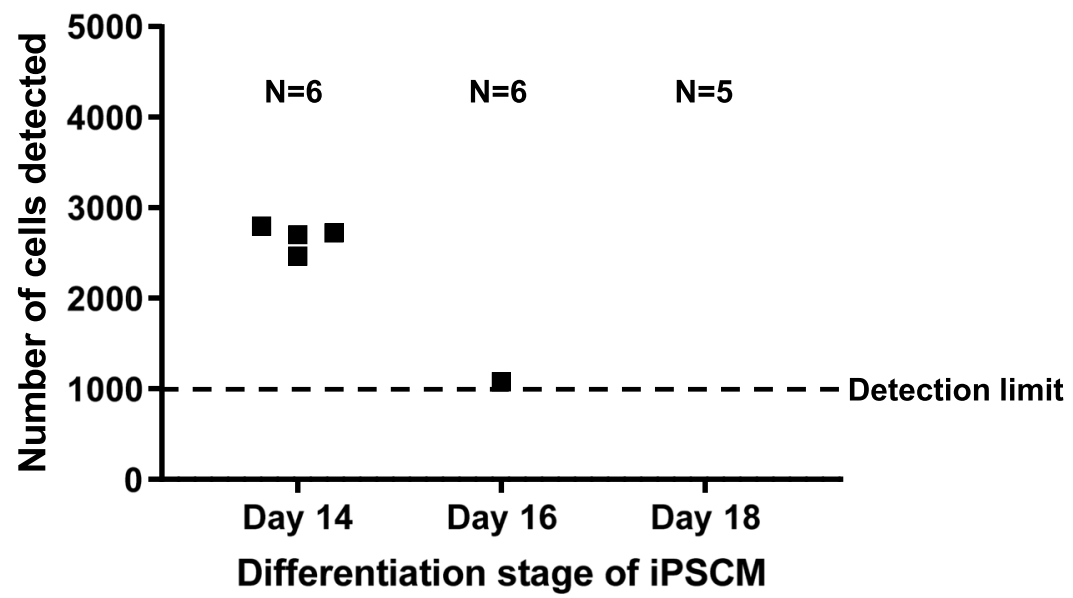

Fig. 3 Adhesion of iPSC-CM to ventricular ECM scaffolds. a Representative picture of decellularized ventricular heart tissue (left) with attached eGFPpositive iPSC-CM (right). Scale bar $100 \mu \mathrm{m}$. b Absolute number of iPSC-CM detected by qPCR. iPSC-CM were added to ECM scaffolds at different time points after starting the differentiation process $(14,16$, and 18 days). The number of attached cells was below the detection limit of the $\mathrm{qPCR}$ in $2 / 6$ samples for iPSC-CM at day 14, 5/6 samples for iPSC-CM at day 16 and all 5 samples for iPSC-CM at day 18 (data points not included in the diagram)

\section{Gene expression analysis}

Most common cardiac integrin subunits $\alpha 1$ (Itga1), $\alpha 5$ (Itga5), $\alpha 7$ (Itga7), $\beta 1$ (Itgb1), and $\beta 8$ (Itgb8) and integrin-binding protein fibulin 1 (Fbln1), fibroblast growth factor 1 (FGF1), and myosin heavy poloypeptide 9 (Myh9) have been analyzed. Integrin subunit genes Itga5, Itga7, and Itgb8 and integrin-binding protein genes Fbln1 and FGF1 showed lower expression levels (at least a 2 -fold change with $p$ values $<0.05$ ) in day 14 iPSC-CM than in day 18 iPSC-CM. Only Myh9 was expressed higher in day 14 iPSC-CM than in day 18 iPSC-CM. No differences in gene expression level $(<2-$ fold change and/or $p>0.05)$ were detected for Intga1, Intga5, and Intgb1 as well as Fbln1 (supplemental Fig. 1 and supplemental Tables 1 and 2).

Gene expression profiles in day 14, day 16, and day 18 iPSC-CM of cardiac gap junction proteins $\alpha 1$ (Gja1; Connexin 43), $\alpha 5$ (Gja5; Connexin 40), and $\gamma 1$ (Gjc1; Connexin 45) were also analyzed. Gja1 and Gjc1 showed no difference $(<2$-fold change and/or $p>0.05)$ in day 14 , day 16, and day 18 iPSC-CM. Gja5 showed slightly lower expression in day 14 than in day $16(-2.14$ fold change, $p=0.005)$ and day $18(-2.23$ fold change, $p=0.002)$
iPSC-CM (supplemental Fig. 2 and supplemental Tables 3 and 4).

\section{Discussion}

Cardiac cell therapy is regarded as a promising approach to regenerate lost myocardium and restore cardiac function in heart failure. iPSC-CM represent a suitable cell type for a true exogenous cell replacement, since they have functional and structural properties like native cardiomyocytes $[4,5]$, can be produced in large numbers $[6$, 7], and reduce immune rejection which would occur with allogeneic cells [38]. Persistence and survival of transplanted cardiomyocytes are of major importance for replacement of lost myocardium, but were reported to be low in previous studies $[14,15,33]$. In the present work, we demonstrate for the first time that the persistence of transplanted iPSC-CM strongly depends on their developmental stage at the time of transplantation and that differences in the capability of iPSC-CM to attach to ECM in vitro correlate with their short-term survival rate in vivo.

It is well known that the developmental stage at the time of transplantation is crucial for the persistence and 


\section{a}

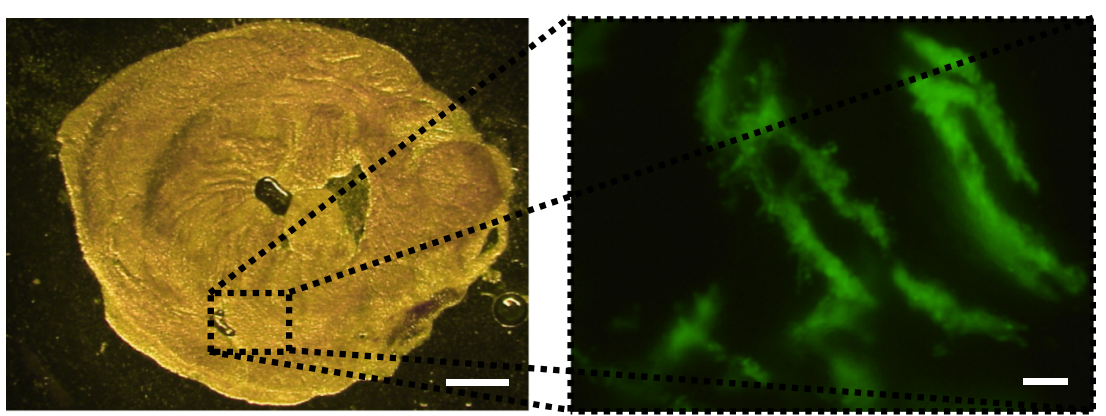

b

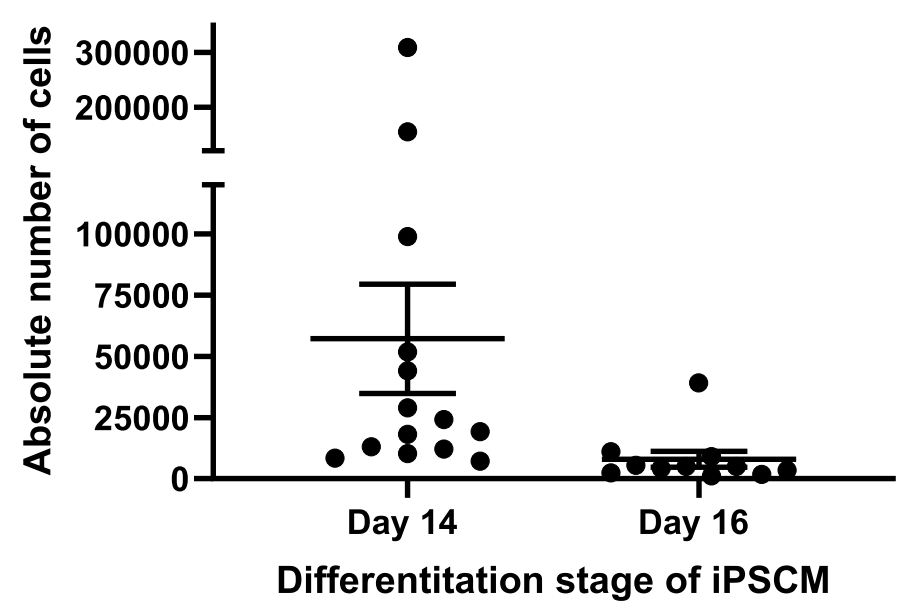

Fig. 4 Cell persistence after transplantation of iPSC-CM in infarcted mouse hearts. a Representative image of eGFP-positive iPSC-CM within a ventricular slice of the recipient heart, 7 days after transplantation. Left scale bar $1 \mathrm{~mm}$, right scale bar $100 \mu \mathrm{m}$. b Number of iPSC-CM assessed by qPCR 6-7 days after injecting $2 \times 500,000$ iPSC-CM in the infarct border zone. iPSC-CM were transplanted at 14 or 16 days after starting the differentiation process. Mean persistence was approximately 7 -fold higher in cells transplanted at day 14 of differentiation compared to day 16 iPSC-CM. Statistical analysis was performed using the Mann-Whitney rank sum test, $p<0.001$

survival of transplanted cells, since dissociated adult cardiomyocytes do not survive transplantation at all [19], while immature cardiomyocytes of different developmental stages have been shown to integrate into the host tissue in many studies $[14,21,22,26]$. But even during maturation, properties of cardiomyocytes undergo substantial changes [23-25, 27] that might influence their fate after transplantation. First evidence of differences in the persistence of immature cardiomyocytes transplanted at different developmental stages was provided by a study that compared fetal cardiomyocytes at day 9.5, day 14.5 , and day 18.5 after injection into mouse hearts [26]. The intermediate stage was most efficient regarding cell persistence and functional integration. Six days after transplantation, the number of transplanted cells was almost 4-fold higher in the intermediate stage than in the late stage and more than 6-fold higher than in the early stage, i.e., the magnitude of the influence of the developmental stage on persistence was comparable to that found in the present study. Day 14.5 of fetal development and day 14 of iPSC-CM differentiation provided the best persistence, which is surprising taking into account the differences between the development of native cardiac tissue and iPSC-CM described before [27], showing that native cardiomyocytes at embryonic days 12-14 have similar electrophysiological characteristics as day 18 murine $\mathrm{PSC}-\mathrm{CM}$ in vitro.

Several mechanisms underlie loss of injected cells, including apoptosis, necrosis, and washout from the injection site $[16,18,19]$. Several studies in large and small animals revealed that more than $90 \%$ of transplanted cells are washed out early after injection [39-41]. This may be linked to the capability of cells to attach to the ECM. Furthermore, lack of interaction between ECM and transplanted cells might induce anoikis [42], which might be prevented by cell adhesion. Cardiomyocytes seem to be very selective for attachment to different substrates in vitro. Pfannkuche et al. tested attachment of ESCM on fibronectin and 18 additional surfaces. These analyses revealed that murine cardiomyocytes attached best on fibronectin-coated plates [43]. In the present study, we first wanted to determine, if the attachment capability to fibronectin differs among iPSC-CM of different developmental stages. The adhesion of iPSC-CM 
a

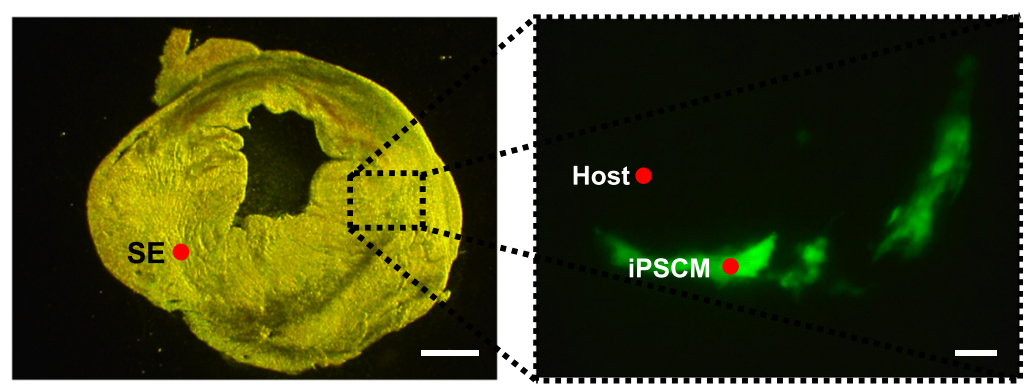

b

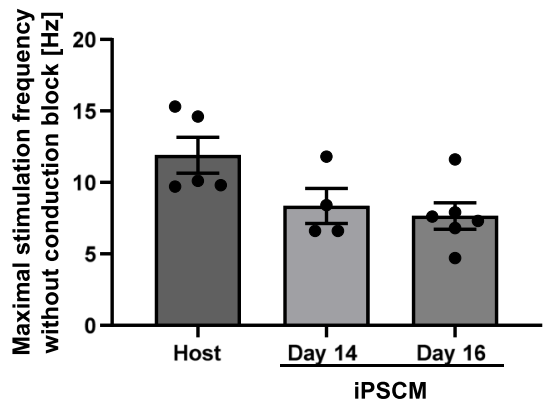

C

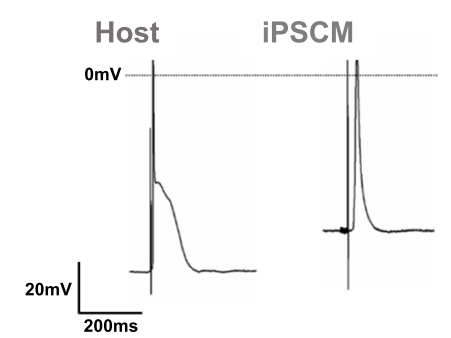

d

\begin{tabular}{ccccccc} 
& $\mathrm{n}$ & Amplitude & $\mathrm{MDP}[\mathrm{mV}]$ & APD50 [ms] & APD90 [ms] & Vmax [V/s] \\
\hline Host & 6 & $83.3 \pm 3.4$ & $-67.0 \pm 3.9$ & $12.6 \pm 1.7$ & $64.5 \pm 4.0$ & $110.6 \pm 16.2$ \\
iPSCM day 14 & 8 & $47.4 \pm 3.4$ & $-45.4 \pm 2.3$ & $15.4 \pm 1.4$ & $54.6 \pm 7.5$ & $30.6 \pm 8.6$ \\
iPSCM day 16 & 8 & $53.2 \pm 5.3$ & $-51.1 \pm 3.2$ & $11.5 \pm 0.9$ & $72.0 \pm 8.3$ & $38.2 \pm 6.6$ \\
\hline
\end{tabular}

e

\begin{tabular}{lccccc} 
p values & Amplitude & MDP & APD50 & APD90 & Vmax \\
\hline Host vs. iPSC-CM & $<0.001$ & $<0.001$ & 0.097 & 0.238 & $<0.001$ \\
Day 14 vs. day 16 & 0.916 & 0.149 & 0.03 & 0.141 & 0.496 \\
\hline
\end{tabular}

Fig. 5 Functional integration of transplanted iPSC-CM into the myocardium. a Representative bright field image of a ventricular heart slice (left picture) with retained eGFP-positive iPSC-CM (right picture) 7 days after injection of $2 \times 0.5 \times 10^{6}$ day 16 iPSC-CM. Left scale bar $1 \mathrm{~mm}$, right scale bar $100 \mu \mathrm{m}$. The positions of the stimulation electrode (SE) and the recordings in host tissue and PSC-CM are marked. $\mathbf{b}$ The quality of electrical integration of day 14 iPSC-CM, day 16 iPSC-CM, and native host cardiomyocytes assessed by the maximal stimulation frequency without conduction block. $\mathbf{c}$ Representative action potentials of a host cardiomyocyte and transplanted iPSC-CM. d Action potential properties of transplanted day 14 iPSC-CM ( $n=6)$, day 16 IPSC-CM $(n=8)$, and host cardiomyocytes $(n=8)$. MDP maximal diastolic potential, Vmax maximal upstroke velocity, APD50 action potential duration at 50\% of repolarization, APD90 action potential duration at $90 \%$ of repolarization. e Statistical analyses of action potential properties. Statistical analysis were performed using one-way ANOVA with post-test for host vs. IPSC-CM and Student's $t$ test for day 14 vs. day 16 iPSC-CM

to fibronectin-coated dishes was numerically higher at day 14 than at day 16 or day 18 of differentiation, but the differences were not statistically significant.

Secondly, since fibronectin-coated plastic dishes do not reflect the complex in vivo ECM composition, attachment of iPSC-CM to decellularized ECM scaffolds was tested and supported the higher focal adhesion capability of day 14 iPCM. However, the number of attached cells was very low and even below the detection level in many samples, which hampered an exact quantification and may be one explanation for the loss of iPSC-CM after transplantation in recipient hearts. One limitation of this model and potential explanation for the low adhesion is that detergents used to decellularize the tissue may have impaired ECM compounds. SDS had a high efficiency in dsDNA removal, but also affected fiber structure of the ECM in a previous study [44], while Triton X-100 retained an intact fiber network, but left a higher amount of dsDNA fragments [45].

Fibronectin, Collagens, and Laminins interact with integrins on the surface of cardiomyocytes to mediate focal cell adhesion. In cardiomyocytes, some of the predominantly expressed integrin heterodimers are $\alpha 1 \beta 1$, $\alpha 5 \beta 1$, and $\alpha 7 \beta 1$, which are the main collagen, fibronectin, and laminin binding receptors [46]. Differences in integrin expression between day 14, day 16, and day 18 iPSC-CM were considered to be one reason for different adhesion capabilities in our experimental settings. However, gene array analysis of day 14, day 16, and day 18 
iPSC-CM did neither reveal relevant differences in $\alpha 1$, $\alpha 5, \alpha 7, \beta 1$, and $\beta 8$ integrin subunit expression nor in integrin binding protein fibulin 1, fibroblast growth factor 1 , and myosin heavy polypeptide 9 protein expression. Thus, the reason for the higher cell adhesion on ECM scaffolds, as well as the higher persistence of day 14 iPSC-CM after transplantation, remains unexplained. Potential explanations, which deserve further investigations in future studies, include differences in integrin expression on the protein level in day 14 vs. older iPSC$\mathrm{CM}$ or morphological differences of the cells, which may influence cell adhesion capabilities. Moreover, stagedependent vulnerability of iPSC-CM to the dissociation process may play a role. Lower rates of apoptosis or necrosis in day 14 iPSC-CM compared to day 16 and day 18 iPSC-CM could enhance the adhesion to extracellular matrix. However, due to the short periods of time used in the in vitro experiments from plating to wash-out of the cells, we consider that neither apoptosis nor necrosis play a major role in the higher adhesion of day 14 iPSC-CM.

A number of techniques have been applied to improve persistence of transplanted cells. Co-injection of biomaterials, which influence the microenvironment after cell transplantation and may close the injection channel, can improve cell retention. Encapsulation of cardiospherederived rat stem cells in hyaluronic acid-serum hydrogels led to a sixfold increased cell persistence after transplantation into non-infarcted rat myocardium [47]. Embedding human cardiac stem cells into a hydrogel matrix also increased long-term retention in mice threefold [48].

Labeling cells with magnetic particles allows cell guidance to an area of interest by applying a magnetic field. Vandergriff et al. demonstrated that magnetic labeling can increase persistence of cardiosphere-derived stem cells inside the infarcted myocardium fourfold [49].

Co-transplantation of mesenchymal stem cells and stem cell-derived cardiomyocytes seems to be highly efficient regarding the improvement of acute retention. The transplantation of in vitro grown microtissue composed of bone marrow-derived murine mesenchymal stem cells and murine ESCM resulted in a more than tenfold increase of cell retention in comparison to single cell suspensions of ESCM 1 day after transplantation [20]. However, there was a highly relevant cell loss at the following 2 days. Moreover, the mean persistence of single cells was very low even at day 1 after transplantation $(0.6 \%$, as compared to average retention of $5.7 \%$ at $6-7$ days after transplantation of day 14 iPSC-CM in the present study).

In our study, iPSC-CM persistence was increased sixfold by using cells at an optimal developmental stage. In comparison to established techniques to improve cell persistence, which require considerable technical efforts, the choice of the optimal developmental stage appears to have a similar or even better effect on persistence and involves few technical efforts.

Besides persistence, the functional integration of transplanted cells is a prerequisite for an efficient cell replacement therapy. The maximal stimulation frequency without conduction blocks, which is a measure of the quality of electrical integration, was reported to be higher in intermediate stage fetal cardiomyocytes than in late stage fetal cardiomyocytes (the early stage could not be analyzed due to the low persistence) [26]. In the present study, the quality of electrical integration of day 14 iPSC-CM was similar and even numerically (but not significantly) higher than that of day 16 iPSC-CM, demonstrating that the improved persistence is not at the expense of functional integration.

The low number of analyzed preparations limited the evaluation of AP properties of iPSC-CM at different stages and host cardiomyocytes. Unlike iPSC-CM, fetal cardiomyocytes show a fast maturation after transplantation and possess adult-like AP properties after 12 days, if they are electrically integrated [21]. The maturation process of fetal cardiomyocytes is mainly characterized by a decrease in APD50 and an increase in APD90. The present study showed significant differences between host $\mathrm{CM}$ and transplanted day 14 and day 16 iPSC-CM 7 days after transplantation, in line with previous studies [22]. However, our AP measurements 7 days after transplantation revealed a significantly lower APD50 in day 16 as compared to day 14 iPSC-CM, which may be an indicator of a higher maturation stage of day 16 iPSC-CM.

The conduction properties of the myocardium depend on the geometry of the connected cells and number, size, and location of gap junction plaques between them [48]. In adult cardiomyocytes, the predominant distribution of gap junctions is end-to-end, located in intercalated discs. Immature cardiomyocytes, like iPSC-CM, show a more homogenous arrangement of connexins over the entire cell surface. After transplantation, the formation of gap junctions between the host and graft tissue is a prerequisitions for electrical integration of the transplanted iPSC$\mathrm{CM}$. The quality of electrical integration was assessed 7 days after transplantation in the present study. Due to the short period, optimal electrical integration was not expected, since one previous study showed an increasing the quality of electrical integration up to 6 to 8 months [22].

Cardiac gap junctions consist of connexins 40,43 , and 45. Gene array results revealed no significant changes in Gja1 (Connexin 43) and Gjc1 (Connexin 45) expression levels. Gja5 (Connexin 40) expression was only slightly lower in day 14 iPSC-CM $(-2.14$ fold change between day 14 and day 16 iPSC-CM), which is consistent with our finding that the quality of electrical integration of day 14 and day 16 iPSC-CM is comparable 7 days after transplantation. 
We used only one murine iPS cell line as a proof-ofprinciple for developmental stage-dependent persistence. The findings of our study might be cell line-specific and especially the exact stage, which offers the highest persistence after transplantation, might be different for different cell lines. In previous studies, we and other groups described substantial functional differences between different stem cell lines [50-52], so we consider it very likely that also persistence and adhesion will be influenced by the choice of cell line. Furthermore, nonmurine cell lines will most probably behave differently, too, so translation into primate models and finally in clinical studies will require an additional investigation of stage-specific effects on persistence.

It is probable that the best stage for transplantation of iPSC-CM will also depend on cell culture and differentiation protocols. Moreover, as iPS cells started cardiac differentiation spontaneously in our experimental setting, not all cells may have attained the same stage of maturation at the same day of differentiation.

We used direct intramyocardial injection of iPSC-CM, which is one method of cell delivery that can be used in humans [53] and is easy to apply in the mouse model. It allows the visualization and precise targeting of the infarct and infarct border zone as well as the delivery of high numbers of cells. However, this technique itself may have an influence on cells persistence. Direct injection creates an injury of the host tissue that may trigger acute inflammatory responses and lead to lower cell survival [54]. Moreover, cell loss through the injection channel into the pericardial space [16] may especially occur in small animal models, where the distance between injection site and pericardial space and the length of the injection channel are very small. However, it is unlikely that this biased the differences in persistence of day 14 as compared to day 16 iPSC-CM, since cells at both developmental stages are similar in size and shape and will be subject to these limitations in a similar way.

We transplanted only day 14 and day 16 iPSC-CM, while we also used day 18 iPSC-CM for the in vitro studies. Earlier studies revealed a loss of cardiac commitment under prolonged culture in cardiac bodies [35]. Therefore, and since cell adhesion to ECM was below the detection level in day 18 iPSC-CM and a low persistence after transplantation was anticipated, we decided not to include day 18 iPSC-CM in the in vivo experiments.

\section{Conclusions}

The present work demonstrates that the developmental stage at the time of transplantation is crucial for the persistence of transplanted murine iPSC-CM. This makes the choice of the optimal developmental stage an important step for a successful clinical translation of iPSC-CM-based therapies.

iPSC-CM at day 14 of differentiation showed the highest persistence after transplantation and the highest capability to adhere to ECM scaffolds in vitro; thus, better adhesion to host tissue and reduced wash out from the injection site may be mechanisms underlying the improved persistence of these cells as compared to more mature cells.

\section{Supplementary Information}

The online version contains supplementary material available at https://doi. org/10.1186/s13287-020-02089-5.

Additional file 1: Supplemental Fig. 1. Gene array data for most common cardiac integrins and integrin binding proteins. All experiments were performed in triplicates made of different cell batches. $P$-values are shown in supplemental Table 2.

Additional file 2: Supplemental Fig. 2. Gene array data for gap junction protein a1 (connexin 43), a5 (connexin 40) and $\gamma 1$ (connexin 45). All experiments were performed in triplicates made of different cell batches. P-values are shown in supplemental Table 4.

Additional file 3. Supplemental methods

Additional file 4: Supplemental Table 1. Gene array data for most common cardiac integrins and integrin binding proteins. Supplemental Table 2. Integrins and integrin binding proteins expression changes. Supplemental Table 3. Gene array data for most common cardiac gap junction proteins. Supplemental Table 4. Gap junction protein expression changes.

\section{Abbreviations}

AP: Action potential; APD50: Action potential duration at 50\% of repolarization; APD90: Action potential duration at 90\% of repolarization; DMEM: Dulbecco's modified Eagle's medium; ECM: Extra cellular matrix; eGFP: Enhanced green fluorescent protein; ESC-CM: Embryonic stem cellderived cardiomyocytes; Fbln1: Fibulin 1; FGF1: Fibroblast growth factor 1; Gja1: Gap junction protein a1; Gja5: Gap junction protein a5; Gjc1: Gap junction protein $\beta 1$; IMDM: Iscove's modified Dulbecco's medium; IRES: Internal ribosomal entry site; Itga1: Integrin a1; Itag5: Integrin a5;

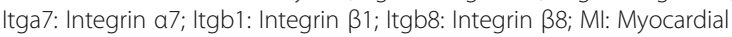
infarction; MDP: Maximal diastolic potential; MSC: Mesenchymal stem cells; PAC: Puromycin N-acetyl-transferase; $\mathrm{PBS}^{-1-}$ : Phosphate-buffered saline without calcium and magnesium; RIVA: Ramus interventricularis anterior; SDS: Sodium dodecyl sulfate; S.E.M.: Standard error of mean; Vmax: Upstroke velocity

\section{Acknowledgements}

We thank Rudolf Jeanisch and Alexander Meissner (Whitehead Institute for Biomedical Research, Cambridge, MA, USA) for providing the murine iPS cell line Tib7.4. We acknowledge the excellent collaboration and the support provided by the animal facility of the University Hospital of Cologne.

\section{Author disclosure statement}

All authors declare that they have no conflict of interest.

\section{Authors' contributions}

GP and MH designed this experimental research. GP and MM performed the experiments. GP, KP, AS, and $\mathrm{MH}$ analyzed and interpreted the data. $\mathrm{KP}, \mathrm{JH}$, $\mathrm{SB}, \mathrm{AS}$, and TS proof-read the manuscript. GP and $\mathrm{MH}$ were the major contributors in writing the manuscript. The authors read and approved the final manuscript.

\section{Funding}

This work was supported by the Marga- und Walter-Boll-Stiftung (Grant 21002-15), Deutsche Forschungsgemeinschaft (DFG, German Research Foundation; Grant HA 3337/4-1) and Koeln Fortune Program/Faculty of Medicine, 
University of Cologne. Open Access funding enabled and organized by Projekt DEAL.

\section{Availability of data and materials}

The datasets used and/or analyzed during the current study are available from the corresponding author on reasonable request.

\section{Ethics approval and consent to participate}

All experiments were approved by the animal welfare officers of the University of Cologne, by the animal welfare officers of the City of Cologne and by the State Office for Nature, Environment and Consumer Protection North Rhine-Westphalia (Landesamt für Natur, Umwelt und Verbraucherschutz Nordrhein-Westfalen; LANUV) in compliance with the Directive 2010/63/EU of the European Parliament.

\section{Consent for publication}

Not applicable

\section{Competing interests}

The authors declare that they have no competing interests.

\section{Author details}

${ }^{1}$ Department of Internal Medicine III, University Hospital of Cologne, Cologne, Germany. ${ }^{2}$ Center for Physiology and Pathophysiology, Institute of

Neurophysiology, Medical Faculty, University of Cologne, Robert-Koch Str. 37, Cologne 50931, Germany. ${ }^{3}$ Marga-and-Walter-Boll Laboratory for Cardiac Tissue Engineering, University of Cologne, Cologne, Germany. ${ }^{4}$ Department of Ophthalmology and Ocular GvHD Competence Center (P.S.), Medical Faculty, University of Cologne, Cologne, Germany. ${ }^{5}$ Department of Pediatric Cardiology, University Hospital of Cologne, Cologne, Germany. ${ }^{6}$ Center for Molecular Medicine, University of Cologne, Cologne, Germany.

\section{Received: 20 August 2020 Accepted: 9 December 2020}

Published online: 08 January 2021

\section{References}

1. Pagidipati NJ, Gaziano TA. Estimating deaths from cardiovascular disease: a review of global methodologies of mortality measurement. Circulation. 2013;127(6):749-56.

2. Takahashi K, Tanabe K, Ohnuki M, Narita M, Ichisaka T, Tomoda K, et al. Induction of pluripotent stem cells from adult human fibroblasts by defined factors. Cell. 2007;131(5):861-72.

3. Okita K, Ichisaka T, Yamanaka S. Generation of germline-competent induced pluripotent stem cells. Nature. 2007:448(7151):313-7.

4. Zhang J, Wilson GF, Soerens AG, Koonce CH, Yu J, Palecek SP, et al. Functional cardiomyocytes derived from human induced pluripotent stem cells. Circ Res. 2009;104(4):e30-41.

5. Narazaki G, Uosaki H, Teranishi M, Okita K, Kim B, Matsuoka S, et al. Directed and systematic differentiation of cardiovascular cells from mouse induced pluripotent stem cells. Circulation. 2008;118(5):498-506.

6. Kattman SJ, Witty AD, Gagliardi M, Dubois NC, Niapour M, Hotta A, et al. Stage-specific optimization of activin/nodal and BMP signaling promotes cardiac differentiation of mouse and human pluripotent stem cell lines. Cell Stem Cell. 2011:8(2):228-40.

7. Tohyama S, Hattori F, Sano M, Hishiki T, Nagahata Y, Matsuura T, et al. Distinct metabolic flow enables large-scale purification of mouse and human pluripotent stem cell-derived cardiomyocytes. Cell Stem Cell. 2013; 12(1):127-37.

8. Yan BB, Singla DK. Transplanted induced pluripotent stem cells mitigate oxidative stress and improve cardiac function through the Akt cell survival pathway in diabetic cardiomyopathy. Mol Pharm. 2013;10(9):3425-32.

9. Singla DK, Long XL, Glass C, Singla RD, Yan BB. Induced pluripotent stem (iPS) cells repair and regenerate infarcted myocardium. Mol Pharm. 2011; 8(5):1573-81.

10. Qin X, Riegler J, Tiburcy M, Zhao X, Chour T, Ndoye B, et al. Magnetic resonance imaging of cardiac strain pattern following transplantation of human tissue engineered heart muscles. Circ Cardiovasclmaging. 2016;9(11): e004731.

11. Weinberger F, Breckwoldt K, Pecha S, Kelly A, Geertz B, Starbatty J, et al. Cardiac repair in guinea pigs with human engineered heart tissue from induced pluripotent stem cells. Sci Transl Med. 2016;8(363):363ra148.
12. Ye $L$, Chang $Y H$, Xiong $Q$, Zhang $P$, Zhang $L$, Somasundaram $P$, et al. Cardiac repair in a porcine model of acute myocardial infarction with human induced pluripotent stem cell-derived cardiovascular cells. Cell Stem Cell. 2014;15(6):750-61.

13. Cyranoski D. 'Reprogrammed' stem cells approved to mend human hearts for the first time. Nature. 2018;557(7707):619-20.

14. Maass M, Krausgrill B, Eschrig S, Kaluschke T, Urban K, Peinkofer G, et al. Intramyocardially transplanted neonatal cardiomyocytes (NCMs) show structural and electrophysiological maturation and integration and dosedependently stabilize function of infarcted rat hearts. Cell Transplant. 2017; 26(1):157-70.

15. Hou D, Youssef EA, Brinton TJ, Zhang P, Rogers P, Price ET, et al. Radiolabeled cell distribution after intramyocardial, intracoronary, and interstitial retrograde coronary venous delivery: implications for current clinical trials. Circulation. 2005:112(9 Suppl):1150-6.

16. Saludas L, Garbayo E, Mazo M, Pelacho B, Abizanda G, Iglesias-Garcia O, et al. Long-term engraftment of human cardiomyocytes combined with biodegradable microparticles induces heart repair. J Pharmacol Exp Ther. 2019:370(3):761-71.

17. Doyle B, Kemp BJ, Chareonthaitawee P, Reed C, Schmeckpeper J, Sorajja P, et al. Dynamic tracking during intracoronary injection of 18F-FDG-labeled progenitor cell therapy for acute myocardial infarction. J Nucl Med. 2007; 48(10):1708-14.

18. Yau TM, Kim C, Ng D, Li G, Zhang Y, Weisel RD, et al. Increasing transplanted cell survival with cell-based angiogenic gene therapy. Ann Thorac Surg. 2005;80(5):1779-86.

19. Reinecke H, Zhang M, Bartosek T, Murry CE. Survival, integration, and differentiation of cardiomyocyte grafts: a study in normal and injured rat hearts. Circulation. 1999;100(2):193-202.

20. Sahito RGA, Sheng X, Maass M, Mikhael N, Hamad S, Heras-Bautista CO, et al. In vitro grown micro-tissues for cardiac cell replacement therapy in vivo. Cell Physiol Biochem. 2019;52(6):1309-24.

21. Halbach M, Pfannkuche K, Pillekamp F, Ziomka A, Hannes T, Reppel M, et al. Electrophysiological maturation and integration of murine fetal cardiomyocytes after transplantation. Circ Res. 2007;101(5):484-92.

22. Halbach M, Peinkofer G, Baumgartner S, Maass M, Wiedey M, Neef K, et al. Electrophysiological integration and action potential properties of transplanted cardiomyocytes derived from induced pluripotent stem cells. Cardiovasc Res. 2013;100(3):432-40.

23. Wang L, Feng ZP, Kondo CS, Sheldon RS, Duff HJ. Developmental changes in the delayed rectifier $\mathrm{K}+$ channels in mouse heart. Circ Res. 1996;79(1):79-85.

24. Wang L, Duff HJ. Developmental changes in transient outward current in mouse ventricle. Circ Res. 1997;81(1):120-7.

25. Nerbonne JM. Regulation of voltage-gated K+ channel expression in the developing mammalian myocardium. J Neurobiol. 1998;37(1):37-59.

26. Halbach M, Baumgartner S, Sahito RG, Krausgrill B, Maass M, Peinkofer G, et al. Cell persistence and electrical integration of transplanted fetal cardiomyocytes from different developmental stages. Int J Cardiol. 2014; 171(3):e122-e4.

27. Peinkofer G, Burkert K, Urban K, Krausgrill B, Hescheler J, Saric T, et al. From early embryonic to adult stage: comparative study of action potentials of native and pluripotent stem cell-derived cardiomyocytes. Stem Cells Dev. 2016;25(19):1397-406.

28. Meissner A, Wernig M, Jaenisch R. Direct reprogramming of genetically unmodified fibroblasts into pluripotent stem cells. Nat Biotechnol. 2007; 25(10):1177-81.

29. Fatima A, Xu G, Nguemo F, Kuzmenkin A, Burkert K, Hescheler J, et al. Murine transgenic iPS cell line for monitoring and selection of cardiomyocytes. Stem Cell Res. 2016:17(2):266-72.

30. Rueden $C T$, Schindelin J, Hiner MC, DeZonia BE, Walter AE, Arena ET, et al ImageJ2: ImageJ for the next generation of scientific image data. BMC Bioinformatics. 2017;18(1):529.

31. Pillekamp F, Halbach M, Reppel M, Rubenchyk O, Pfannkuche K, Xi JY, et al. Neonatal murine heart slices. A robust model to study ventricular isometric contractions. Cell Physiol Biochem. 2007;20(6):837-46.

32. Peinkofer $G$, Hescheler J, Halbach M. Murine short axis ventricular heart slices for electrophysiological studies. J Vis Exp. 2017;124:e55725.

33. Muller-Ehmsen J, Whittaker P, Kloner RA, Dow JS, Sakoda T, Long TI, et al. Survival and development of neonatal rat cardiomyocytes transplanted into adult myocardium. J Mol Cell Cardiol. 2002;34(2):107-16. 
34. Meganathan K, Jagtap S, Wagh V, Winkler J, Gaspar JA, Hildebrand D, et al. Identification of thalidomide-specific transcriptomics and proteomics signatures during differentiation of human embryonic stem cells. PLoS One. 2012;7(8):e44228.

35. Heras-Bautista CO, Katsen-Globa A, Schloerer NE, Dieluweit S, Abd El Aziz $\mathrm{OM}$, Peinkofer $\mathrm{G}$, et al. The influence of physiological matrix conditions on permanent culture of induced pluripotent stem cell-derived cardiomyocytes. Biomaterials. 2014;35(26):7374-85.

36. Roell W, Lu ZJ, Bloch W, Siedner S, Tiemann K, Xia Y, et al. Cellular cardiomyoplasty improves survival after myocardial injury. Circulation. 2002; 105(20):2435-41.

37. Halbach M, Pillekamp F, Brockmeier K, Hescheler J, Muller-Ehmsen J, Reppel M. Ventricular slices of adult mouse hearts - a new multicellular in vitro model for electrophysiological studies. Cell Physiol Biochem. 2006;18(1-3):1-8.

38. Kashiyama N, Miyagawa S, Fukushima S, Kawamura T, Kawamura A, Yoshida $\mathrm{S}$, et al. MHC-mismatched allotransplantation of induced pluripotent stem cell-derived cardiomyocyte sheets to improve cardiac function in a primate ischemic cardiomyopathy model. Transplantation. 2019;103(8):1582-90.

39. van den Akker F, Feyen DAM, van den Hoogen $P$, van Laake $L$, van Eeuwijk ECM, Hoefer I, et al. Intramyocardial stem cell injection: go(ne) with the flow. Eur Heart J. 2017;38(3):184-6.

40. Freyman T, Polin G, Osman H, Crary J, Lu MM, Cheng L, et al. A quantitative, randomized study evaluating three methods of mesenchymal stem cell delivery following myocardial infarction. Eur Heart J. 2006;27(9):1114-22.

41. Lang C, Lehner S, Todica A, Boening G, Franz WM, Bartenstein P, et al. Positron emission tomography based in-vivo imaging of early phase stem cell retention after intramyocardial delivery in the mouse model. Eur J Nucl Med Mol I. 2013;40(11):1730-8.

42. Frisch $\mathrm{SM}$, Francis $\mathrm{H}$. Disruption of epithelial cell-matrix interactions induces apoptosis. J Cell Biol. 1994;124(4):619-26.

43. Pfannkuche K, Neuss S, Pillekamp F, Frenzel LP, Attia W, Hannes T, et al. Fibroblasts facilitate the engraftment of embryonic stem cell-derived cardiomyocytes on three-dimensional collagen matrices and aggregation in hanging drops. Stem Cells Dev. 2010;19(10):1589-99.

44. Cebotari S, Tudorache I, Jaekel T, Hilfiker A, Dorfman S, Ternes W, et al, Detergent decellularization of heart valves for tissue engineering: toxicological effects of residual detergents on human endothelial cells. Artif Organs. 2010;34(3):206-10

45. White LJ, Taylor AJ, Faulk DM, Keane TJ, Saldin LT, Reing JE, et al. The impact of detergents on the tissue decellularization process: a ToF-SIMS study. Acta Biomater. 2017;50:207-19.

46. Israeli-Rosenberg S, Manso AM, Okada H, Ross RS. Integrins and integrinassociated proteins in the cardiac myocyte. Circ Res. 2014;114(3):572-86.

47. Chan AT, Karakas MF, Vakrou S, Afzal J, Rittenbach A, Lin X, et al. Hyaluronic acid-serum hydrogels rapidly restore metabolism of encapsulated stem cells and promote engraftment. Biomaterials. 2015;73:1-11.

48. Mayfield AE, Tilokee EL, Latham N, McNeill B, Lam BK, Ruel M, et al. The effect of encapsulation of cardiac stem cells within matrix-enriched hydrogel capsules on cell survival, post-ischemic cell retention and cardiac function. Biomaterials. 2014:35(1):133-42.

49. Vandergriff AC, Hensley TM, Henry ET, Shen DL, Anthony S, Zhang JY, et al. Magnetic targeting of cardiosphere-derived stem cells with ferumoxytol nanoparticles for treating rats with myocardial infarction. Biomaterials. 2014; 35(30):8528-39.

50. Sheng X, Reppel M, Nguemo F, Mohammad Fl, Kuzmenkin A, Hescheler J, et al. Human pluripotent stem cell-derived cardiomyocytes: response to TTX and lidocain reveals strong cell to cell variability. PLoS One. 2012;7(9): e45963.

51. Pfannkuche $K$, Liang $H$, Hannes T, Xi J, Fatima A, Nquemo F, et al. Cardiac myocytes derived from murine reprogrammed fibroblasts: intact hormonal regulation, cardiac ion channel expression and development of contractility. Cell Physiol Biochem. 2009;24(1-2):73-86.

52. Hannes T, Wolff M, Doss MX, Pfannkuche $K$, Haustein M, Muller-Ehmsen $J$, et al. Electrophysiological characteristics of embryonic stem cellderived cardiomyocytes are cell line-dependent. Cell Physiol Biochem. 2015;35(1):305-14.

53. Smits PC, van Geuns RJM, Poldermans D, Bountioukos M, Onderwater EEM, Lee $\mathrm{CH}$, et al. Catheter-based intramyocardial injection of autologous skeletal myoblasts as a primary treatment of ischemic heart failure - clinical experience with six-month follow-up. J Am Coll Cardiol. 2003;42(12):2063-9.

54. Suzuki K, Murtuza B, Beauchamp JR, Brand NJ, Barton PJ, Varela-Carver $A$, et al. Role of interleukin-1beta in acute inflammation and graft death after cell transplantation to the heart. Circulation. 2004;110(11 Suppl 1): |l219-24.

\section{Publisher's Note}

Springer Nature remains neutral with regard to jurisdictional claims in published maps and institutional affiliations.
Ready to submit your research? Choose BMC and benefit from:

- fast, convenient online submission

- thorough peer review by experienced researchers in your field

- rapid publication on acceptance

- support for research data, including large and complex data types

- gold Open Access which fosters wider collaboration and increased citations

- maximum visibility for your research: over $100 \mathrm{M}$ website views per year

At BMC, research is always in progress.

Learn more biomedcentral.com/submissions 